\title{
TOTAL REPAIR OF PULMONARY ATRESIA WITH VENTRICULAR SEPTAL DEFECT AND MAJOR AORTOPULMONARY COLLATERALS: AN INTEGRATED APPROACH
}

Adriano Carotti, MD

Roberto M. Di Donato, MDa

Cosimo Squitieri, $\mathrm{MD}^{\mathrm{a}}$

Paolo Guccione, $\mathrm{MD}^{\mathrm{b}}$

Glauco Catena, $\mathrm{MD}^{\mathrm{c}}$

Sponsor: Aldo R. Castañeda, MD
Background: Predicting postrepair right ventricular/left ventricular pressure ratio has prognostic relevance for patients undergoing total repair of pulmonary atresia, ventricular septal defect, and major aortopulmonary collateral arteries. To this purpose, we currently rely on 2 novel parameters: (1) preoperative total neopulmonary arterial index and (2) mean pulmonary artery pressure changes during an intraoperative flow study. Methods: Since January 1994, 15 consecutive patients (aged $64 \pm$ 54 months) with pulmonary atresia, ventricular septal defect, and major aortopulmonary collaterals were managed according to total neopulmonary arterial index. Seven patients with hypoplastic pulmonary arteries and a total neopulmonary arterial index less than $150 \mathrm{~mm}^{2} / \mathrm{m}^{2}$ underwent palliative right ventricular outflow tract reconstruction followed by secondary 1-stage unifocalization and ventricular septal defect closure. The other 8 patients with a preoperative index of more than 150 $\mathrm{mm}^{2} / \mathrm{m}^{2}$ underwent primary single-stage unifocalization and repair. The ventricular septal defect was closed in all cases (reopened in 1). In 9, such decision was based on an intraoperative flow study. Results: Patients treated by right ventricular outflow tract reconstruction had a significant increase of pulmonary artery index $(P=.006)$ within $22 \pm 6$ months. Repair was successful in 14 cases (postrepair right ventricular/left ventricular pressure ratio $=0.47 \pm 0.1$ ). One hospital death occurred as a result of pulmonary vascular obstructive disease, despite a reassuring intraoperative flow study. Accuracy of this test in predicting the postrepair mean pulmonary artery pressure was 89\% (95\% CI: $51 \%-99 \%)$. At follow-up (18 \pm 12 months), all patients are free of symptoms, requiring no medications. Conclusion: The integrated approach to total repair of pulmonary atresia, ventricular septal defect, and major aortopulmonary collaterals by preoperative calculation of total neopulmonary arterial index, right ventricular outflow tract reconstruction (when required), and intraoperative flow study may lead to optimal intermediate results. (J Thorac Cardiovasc Surg 1998;116:914-23)
S urgery for pulmonary atresia with ventricular septal defect and major aortopulmonary collateral arteries (PA, VSD, and MAPCAs) has markedly evolved in the past decade. Traditionally, palliations promoting pulmonary arterial growth ${ }^{1-3}$ or staged unifocalizations, ${ }^{4-9}$ or both were performed in preparation for subsequent

From the Divisions of Pediatric Cardiac Surgery, ${ }^{a}$ Pediatric Cardiology, ${ }^{\mathrm{b}}$ and Pediatric Cardiac Anesthesia, ${ }^{\mathrm{c}}$ Department of Pediatric Cardiology and Cardiac Surgery, Bambino Gesù Hospital, Rome, Italy.

Read at the Seventy-eighth Annual Meeting of The American Association for Thoracic Surgery, Boston, Mass, May 3-6, 1998.

Received for publication May 8, 1998; revisions requested July 16, intracardiac repair. ${ }^{5,7,10}$ Cumulative results, however, were mostly unsatisfactory in terms of either morbidity/ mortality or function. ${ }^{4-7}$

Recently, 1-stage complete unifocalization, through both a midline and a clamshell approach, has been achieved regardless of true pulmonary arterial anatomy.

1998; revisions received Aug 4, 1998; accepted for publication Aug 6, 1998.

Address for reprints: Adriano Carotti, MD, Department of Pediatric Cardiology and Cardiac Surgery, Ospedale Bambino Gesù, Piazza S Onofrio, 4, 00165 Rome, Italy.

Copyright (C) 1998 by Mosby, Inc.

0022-5223/98 \$5.00+ $0 \quad \mathbf{1 2 / 6 / 9 3 6 5 7}$ 
Concomitant intracardiac repair was possible in $80 \%$ to $100 \%$ of these cases. ${ }^{11-13}$ Single-stage unifocalization and repair can most often be guided by either morphologic preoperative criteria or intraoperative functional data. ${ }^{14}$ Different treatments should be contemplated, however, for patients with dominant, or exclusive, MAPCAs as opposed to those with dominant, yet severely hypoplastic, pulmonary arteries. ${ }^{15} \mathrm{We}$ have recently adopted both preoperative morphometric and intraoperative physiologic criteria, in the framework of a novel integrated approach.

\section{Patients and methods}

Between January 1994 and October 1997, 15 consecutive patients with PA, VSD, and MAPCAs, aged 2 months to 13 years, underwent surgical treatment (Table I). Six (40\%) were less than 24 months of age, $6(40 \%)$ were between 2 and 9 years of age, and $3(20 \%)$ were between 9 and 13 years of age. One patient had congenital heart block. All patients underwent 2-dimensional echocardiography and hemodynamic evaluation.

Evaluation of MAPCAs and pulmonary arteries. MAPCAs were first investigated by a descending aortogram, followed by selective pressure measurements and angiography. Native pulmonary arteries were visualized by retrograde filling from a MAPCA injection or a pulmonary venous wedge injection and by direct filling via a collateral or a previous shunt. Both MAPCAs and native pulmonary arteries (when present) were classified for size, number of lung segments perfused, and areas of dual pulmonary blood supply. True pulmonary arteries were measured immediately before their bifurcation, according to Nakata and associates, ${ }^{16}$ whereas MAPCAs were measured distal to the stenoses considered surgically accessible, that is, within the lobar level. The indexed cross-sectional areas of pulmonary arteries (PAI = pulmonary artery index) and of MAPCAs (CAI = total MAPCA index), as well as their sum, the total neopulmonary artery index $(\mathrm{TNPAI}=\mathrm{CAI}+\mathrm{PAI})$, were calculated for each patient. ${ }^{14}$

Surgical policy. In our previous experience with PA and VSD repair, we considered $150 \mathrm{~mm}^{2} / \mathrm{m}^{2}$ as the minimal PAI acceptable for VSD closure. ${ }^{17}$ Similarly, in our more recent experience with PA, VSD, and MAPCAs we elected a TNPAI cutoff value of more than $150 \mathrm{~mm}^{2} / \mathrm{m}^{2}$ for complete repair. Characteristics of MAPCAs and pulmonary artery morphology are reported in Tables II, III, and IV.

Seven patients with TNPAI less than $150 \mathrm{~mm}^{2} / \mathrm{m}^{2}$ had very small $(<2.5 \mathrm{~mm}$ in size) to small $(>2.5 \mathrm{~mm}$ in size, but PAI $<$ $100 \mathrm{~mm}^{2} / \mathrm{m}^{2}$ ) pulmonary arteries (Table II) supplying, on average, most pulmonary segments (Table III).

Eight patients with TNPAI greater than $150 \mathrm{~mm}^{2} / \mathrm{m}^{2}$ (Table II) had absent pulmonary arteries $(\mathrm{n}=2)$ or absent right pulmonary artery $(n=1)$ or small $(n=3)$ to medium-sized confluent central pulmonary arteries (PAI $>100 \mathrm{~mm}^{2} / \mathrm{m}^{2}, \mathrm{n}=2$ ). MAPCAs were the only source of pulmonary blood flow for
Table I. Patient population $(n=15)$

\begin{tabular}{ll}
\hline Age & \\
Mean \pm SD & $64 \pm 54$ mo \\
Median & 58 mo \\
Range & 2 mo-13 y \\
Sex, male/female & $7: 8$ \\
Weight $(\mathrm{kg})$ & \\
Mean \pm SD & $16.7 \pm 8.4$ \\
Median & 13.5 \\
Range & $4.2-34$ \\
Previous operations (No. of patients) & 3 \\
Central shunt & 3 \\
Epicardial pacemaker implantation & 1 \\
Shunt to a MAPCA & 1 \\
\hline
\end{tabular}

one ( $n=1)$ or both lungs $(n=2)$, or they supplied terminally the majority of lung segments $(\mathrm{n}=5)$ (Table III).

Palliative right ventricular outflow tract reconstruction. Patients with TNPAI $<150 \mathrm{~mm}^{2} / \mathrm{m}^{2}$ underwent reconstruction of the right ventricular outflow tract (RVOT) to promote the growth of native pulmonary arteries by establishing forward flow.

Cardiopulmonary bypass was instituted by aorta-bicaval cannulation and left atrial venting. While the patient was cooled to $22^{\circ} \mathrm{C}$, with the lungs ventilated and the heart ejecting and without the collaterals being occluded, the pulmonary arteries were thoroughly dissected free and distally clip-occluded.

RVOT reconstruction was accomplished by a small pulmonary valved homograft in patients with very small pulmonary arteries $(n=2)$ and by either prosthetic (polytetrafluoroethylene or Dacron) conduit $(\mathrm{n}=3$ ) or a short transannular RVOT patch $(\mathrm{n}=2)$ in patients with small pulmonary arteries $(n=5)$. A short period of aortic crossclamping was used in all to prevent air embolism through the ventriculotomy.

Primary 1-stage complete unifocalization and repair. Patients with a TNPAI greater than $150 \mathrm{~mm}^{2} / \mathrm{m}^{2}$ underwent 1 stage midline complete unifocalization and repair.

After a generous flap of anterior pericardium had been retrieved, the posterior mediastinum was dissected by means of the transverse sinus approach, ${ }^{11}$ without the pleura being opened. Collaterals anterior to the airway were followed upstream to their aortic origin, whereas those posterior to the airway, especially the left-sided ones, were dissected downstream from their aortic origin. Esophageal retraction was often necessary for dissection of MAPCAs opposite the side of the aortic arch. Once all collaterals were controlled, they were snared and cardiopulmonary bypass was begun. While the patient was being cooled to $30^{\circ} \mathrm{C}$, the decompressed collaterals were further dissected distally, ligated at their origin, transected, taken anteriorly to the airway (when required), and unifocalized. All unifocalizations were performed by favoring native tissue-to-tissue anastomoses and avoiding prosthetic material in the periphery. ${ }^{11}$ In only 1 case, early in our experience, was a polytetrafluoroethylene conduit used to unifocalize a left lower lobe collateral with a long-segment distal stenosis. 
Table II. Patient demographics according to TNPAI

\begin{tabular}{|c|c|c|c|c|c|c|}
\hline & \multicolumn{3}{|c|}{$T N P A I<150(n=7)$} & \multicolumn{3}{|c|}{$T N P A I \geq 150(n=8)$} \\
\hline & Mean $\pm S D$ & Median & Range & Mean $\pm S D$ & Median & Range \\
\hline \multicolumn{7}{|l|}{ Age (mo) } \\
\hline At RVOTR & $35.1 \pm 53.9$ & 18 & $2-156$ & - & - & - \\
\hline At repair* & $57.3 \pm 51.8$ & 43 & $14-172$ & $90.3 \pm 42.9$ & 84 & $21-154$ \\
\hline \multicolumn{7}{|l|}{ Weight (kg) } \\
\hline At RVOTR & $12.9 \pm 9.8$ & 11 & $4.2-34$ & - & - & - \\
\hline At repair $\dagger$ & $19.5 \pm 13.3$ & 16 & $6.7-48$ & $20 \pm 5.7$ & 19 & $12-28$ \\
\hline
\end{tabular}

TNPAI, Total neopulmonary arterial index $\left(\mathrm{mm}^{2} / \mathrm{m}^{2}\right) ; R V O T R$, right ventricular outflow tract reconstruction.

$* P$ value $(\mathrm{t})=.2$.

$\dagger P$ value $(\mathrm{t})=.9$.

Table III. Characteristics of pulmonary vascular supply

\begin{tabular}{lll}
\hline & $\begin{array}{c}T N P A I<150 \\
(n=7)\end{array}$ & $\begin{array}{c}T N P A I \geq 150 \\
(n=8)\end{array}$ \\
\hline $\begin{array}{l}\text { No. of MAPCAs per patient } \\
\text { Mean } \pm \text { SD }\end{array}$ & $2.3 \pm 0.9$ & $3.6 \pm 1.6$ \\
Median & 2 & 4 \\
$\quad$ Range & $1-4$ & $1-6$ \\
No. of lung segments & & \\
supplied by MAPCAs & & \\
Mean \pm SD & $6.1 \pm 1.1$ & $11.4 \pm 5.8$ \\
Median & 7 & 9.5 \\
Range & $5-7$ & $4-20$ \\
No. of lung segments & & \\
supplied by PAs & & \\
Mean \pm SD & $13.9 \pm 1.1$ & $8.6 \pm 5.8$ \\
Median & 13 & 10 \\
Range & $13-15$ & $0-16$ \\
\hline
\end{tabular}

TNPAI, Total neopulmonary arterial index $\left(\mathrm{mm}^{2} / \mathrm{m}^{2}\right) ;$ MAPCAs, major aortopulmonary collateral arteries; $P A s$, pulmonary arteries.

In general, tissue-to-tissue anastomosis was achieved in 2 different ways: (1) end-to-side or side-to-side anastomosis of a MAPCA to a native pulmonary artery or to other MAPCAs (Figs 1, $C^{*}$ and 2, $C^{*}$ ) and (2) side-to-side posterior anastomosis of a MAPCA to a native pulmonary artery or to another MAPCA with anterior patch augmentation of untreated autologous pericardium (Fig 1, $C^{* *}$ ). Ligation was limited to those collaterals perfusing areas of lung with dual blood supply, which were not considered useful for augmentation of hypoplastic pulmonary arteries (Fig 1, $C^{* * * *}$ ).

During further cooling to $25^{\circ} \mathrm{C}$, a valved homograft (either pulmonary or aortic) was distally anastomosed to the pulmonary confluence (Figs 1, $C$ and 2,C). The aorta was then crossclamped and blood cardioplegic solution was administered. The VSD was patch-closed through a longitudinal right ventriculotomy. The atrial communication was closed in all but 1 case, in which a small 1-way atrial septal defect was created. After the aortic crossclamp was released, the homograft was proximally anastomosed to the right ventricle with a bovine pericardium hood augmentation. A pressure line was placed transatrially into the pulmonary arteries and kept in place for 48 hours. Thereafter, withdrawal pressure recordings and
Table IV. Indexed cross-sectional measurements

\begin{tabular}{lll}
\hline & $\begin{array}{c}\text { TNPAI }<150 \\
(n=7)\end{array}$ & $\begin{array}{c}T N P A I \geq 150 \\
(n=8)\end{array}$ \\
\hline CAI & & \\
Mean \pm SD & $73.9 \pm 28.3$ & $130.4 \pm 122.8$ \\
Median & 72 & 82 \\
Range & $41-110$ & $20-319.5$ \\
PAI & & \\
Mean \pm SD & $46.3 \pm 26$ & $132.6 \pm 126.6$ \\
Median & 48 & 90 \\
Range & $15.7-89.2$ & $0-355$ \\
TNPAI & & \\
Mean \pm SD & $120.2 \pm 10$ & $262.9 \pm 77.7$ \\
Median & 123 & 247 \\
Range & $100.6-130.2$ & $151-364$ \\
\hline
\end{tabular}

TNPAI, Total neopulmonary arterial index $\left(\mathrm{mm}^{2} / \mathrm{m}^{2}\right) ; C A I$, total MAPCA index $\left(\mathrm{mm}^{2} / \mathrm{m}^{2}\right) ;$ MAPCA, major aortopulmonary collateral artery; PAI, pulmonary artery index $\left(\mathrm{mm}^{2} / \mathrm{m}^{2}\right)$.

blood samplings were performed to rule out residual intracardiac left-to-right shunting or RVOT obstruction, or both.

Secondary 1-stage complete unifocalization and repair. Patients showing significant growth of central pulmonary arteries after initial RVOT reconstruction (acquired TNPAI > $150 \mathrm{~mm}^{2} / \mathrm{m}^{2} ; \mathrm{n}=7$ ) underwent secondary midline 1-stage complete unifocalization and repair, based on the aforementioned criteria. The operative technique slightly differed, however, in that the previously reconstructed RVOT, whether by conduit or by outflow patch, was divided and its proximal stump temporarily oversewn to avoid both systemic air embolism and blood leakage into the operative field.

Intraoperative flow study. In 9 patients undergoing repair (primary, 7; secondary, 2), an intraoperative compliance test of the unifocalized pulmonary arterial tree was carried out with the use of incremental transpulmonary flow challenges, according to Reddy and associates. ${ }^{14}$ The flow study was routinely performed before aortic crossclamping, at a temperature of $25^{\circ} \mathrm{C}$, with beating heart and collapsed lungs. Care was taken to push the left atrial vent well into the left ventricle to avoid pulmonary artery pressure misreadings. The decision to close the VSD was based on a mean pulmonary artery pres- 

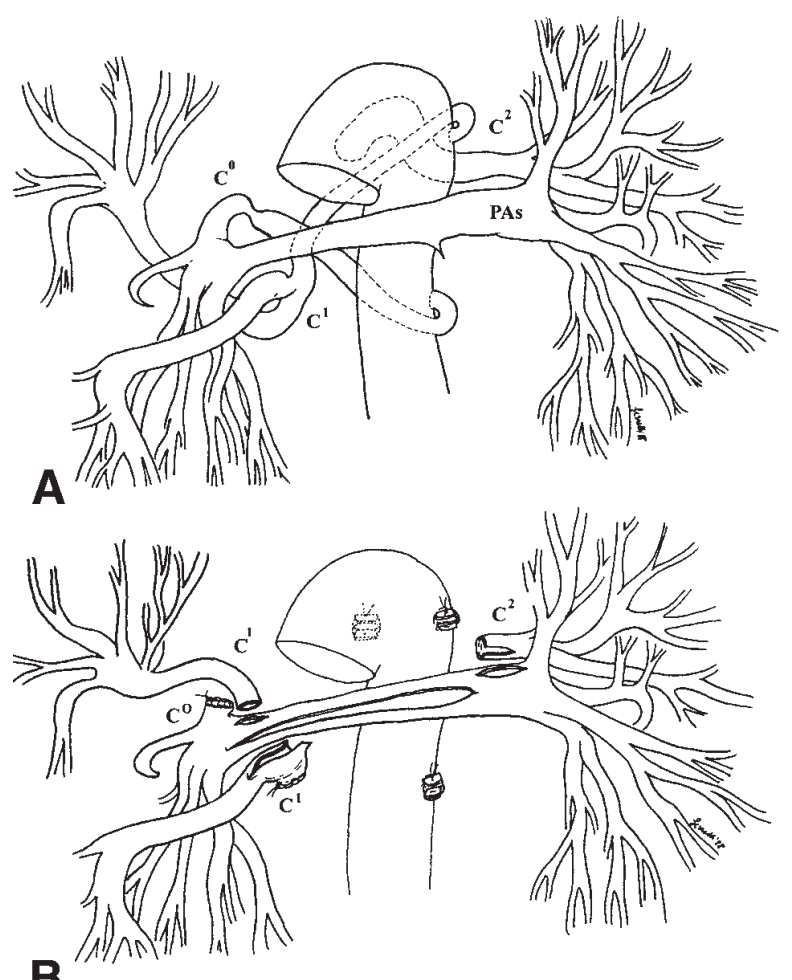

B

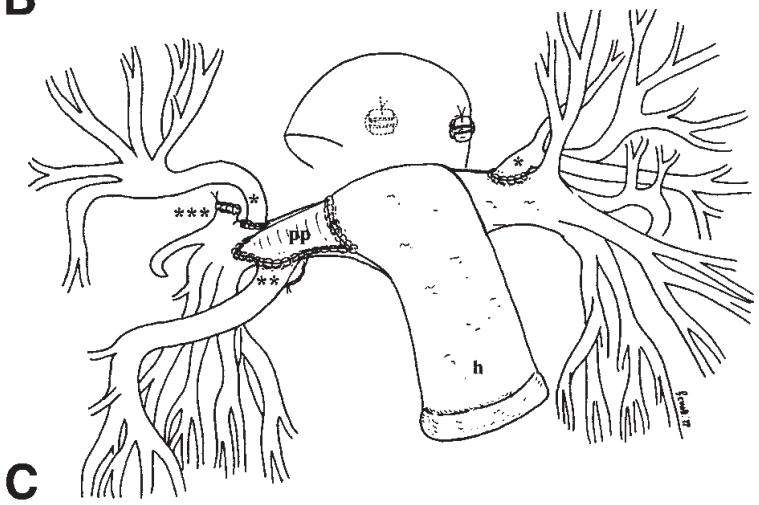

Fig 1. Surgical technique for 1-stage unifocalization in the presence of native pulmonary arteries. A, Anatomic features of native pulmonary arteries $(P A s)$ and major aortopulmonary collateral arteries $\left(\mathrm{c}^{0}\right.$, anastomotic-type; $\mathrm{c}^{1}$, bifurcated terminal-type; $\mathrm{c}^{2}$, terminal type). B, Scheme of unifocalization: $\mathrm{c}^{0}$, $\mathrm{c}^{1}$, and $\mathrm{c}^{2}$ are closed with double pledget-supported sutures at their aortic origin; $\mathrm{c}^{0}$ is transected and its pulmonary side is oversewn; $\mathrm{c}^{1}$ and $\mathrm{c}^{2}$ are transected and longitudinally opened; PAs are longitudinally opened. C, Final result (*tissue-to-tissue anastomosis; **posterior tissue-to-tissue anastomosis with anterior patch augmentation; *** suture ligation; $p p$, autologous pericardial patch; $h$, homograft).

sure of less than or equal to $30 \mathrm{~mm} \mathrm{Hg}$ with a transpulmonary predicted cardiac index of $2.5 \mathrm{~L} / \mathrm{min}$ per square meter.

Chromosome 22q11 microdeletion. All patients were screened from both a phenotypic and genotypic viewpoint. Chromosome 22q11 microdeletion, detected by fluorescent in situ hybridization, was present in 4 patients $(27 \%)$. Its
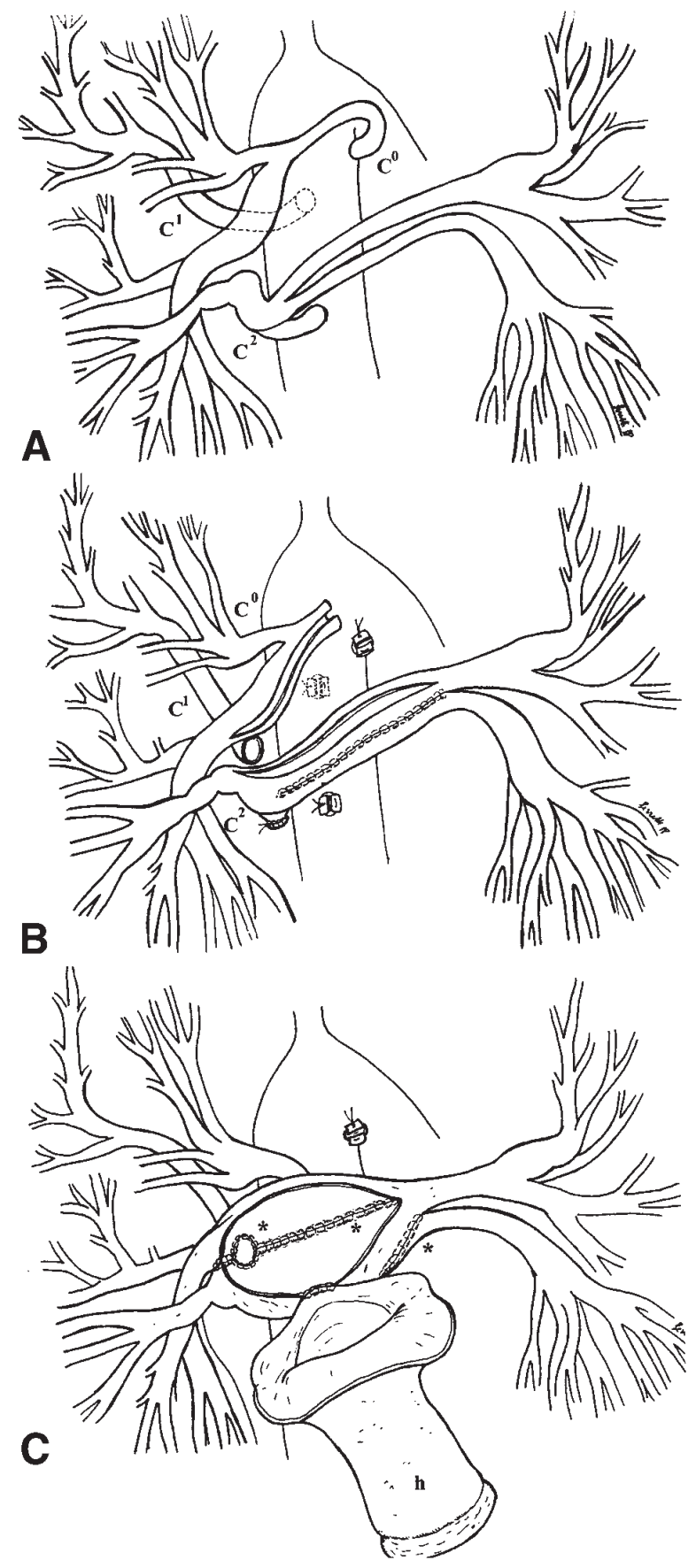

Fig 2. Surgical technique for 1-stage unifocalization in the absence of native pulmonary arteries. A, Anatomic features of MAPCAs ( $c^{0}$ and $\mathrm{c}^{1}$, terminal-type; $\mathrm{c}^{2}$, trifurcated terminal-type). B, Scheme of unifocalization: $\mathrm{c}^{0}, \mathrm{c}^{1}$, and $\mathrm{c}^{2}$ are closed with double pledget-supported sutures at their aortic origin; $\mathrm{c}^{0}$ and all 3 branches of $\mathrm{c}^{2}$ are longitudinally opened; left-sided branches of $\mathrm{c}^{2}$ are sutured side to side. $\mathbf{C}$, Final result (*tissue-to-tissue anastomosis; $h$, homograft).

occurrence did not relate to any peculiar anatomic phenotype, neither regarding pulmonary vascular supply (characteristics of pulmonary arteries, number of MAPCAs, TNPAI at pre- 


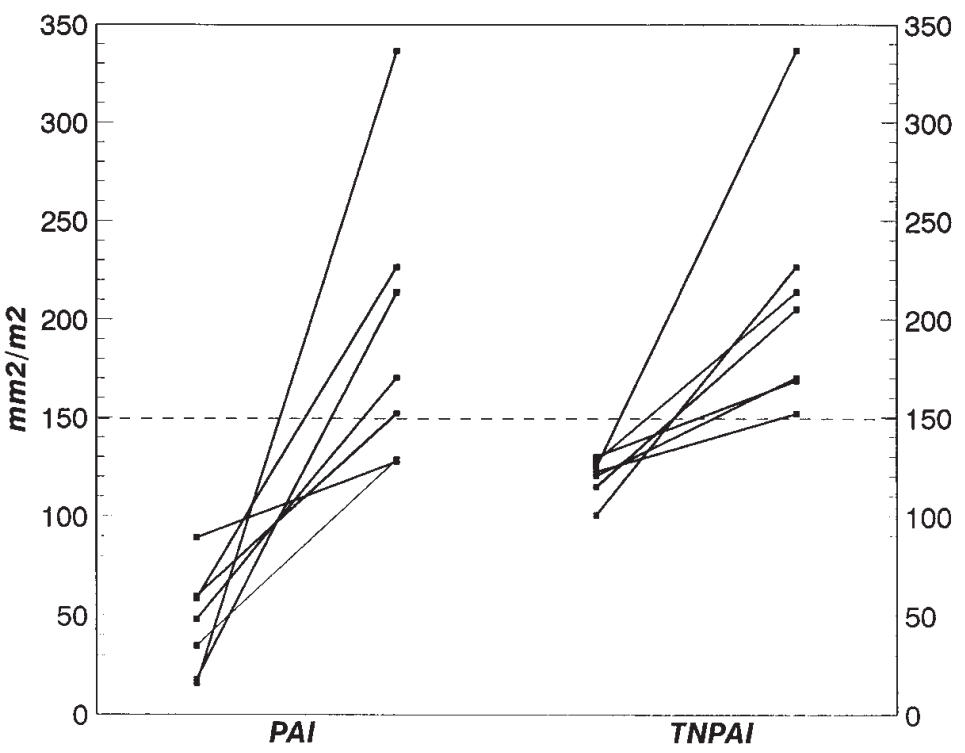

Fig 3. PAI and TNPAI evolution after RVOT reconstruction. Dotted line, cutoff value for complete repair (see text).

Table V. Operative data for total repair $(n=14)$

\begin{tabular}{ll}
\hline Cardiopulmonary bypass time (min) & \\
Mean & $325 \pm 36$ \\
Median & 322 \\
Range & $255-380$ \\
Crossclamping time (min) & \\
Mean & $58 \pm 12$ \\
Median & 56 \\
Range & $43-82$ \\
pRV/pLV (end of bypass) & \\
Mean & $0.47 \pm 0.1$ \\
Median & 0.49 \\
Range & $0.3-0.65$ \\
\hline
\end{tabular}

$p R V / p L V$, Right ventricular/left ventricular pressure ratio.

sentation) nor occurrence of a right aortic arch. ${ }^{18}$ There was only a slight difference in the incidence of infundibular atresia in these patients compared with those without 22q11 deletion $(50 \%$ vs $18 \%: P=.5)$.

Follow-up. At discharge all patients underwent 2-dimensional Doppler echocardiographic evaluation of the repair. All have been followed-up by clinical check-up, echocardiogram, and, whenever possible, by elective cardiac catheterization $(n=11)$ and nuclear perfusion scan $(n=4)$.

Data analysis. Descriptive statistics are expressed as mean \pm standard deviation (SD), median and range, or $95 \%$ confidence intervals (CI). Student paired $t$ test was performed with the use of SPSS for Windows version 7.0 (SPSS Inc, Chicago, Ill).

\section{Results}

RVOT reconstruction. All 7 patients who underwent RVOT reconstruction had significant growth of central pulmonary arteries, within $22 \pm 6$ months of the palliation (median 24, range 12-30 months). The mean PAI increased from $46 \pm 26 \mathrm{~mm}^{2} / \mathrm{m}^{2}$ (median 48 , range 16-89) to $194 \pm 74 \mathrm{~mm}^{2} / \mathrm{m}^{2}$ (median 170 , range 128 337) $(P=.006)$. The acquired TNPAI after the palliation always exceeded $150 \mathrm{~mm}^{2} / \mathrm{m}^{2}$ (Fig 3), allowing secondary 1-stage complete unifocalization and repair.

Repair: Early results. All 15 patients underwent primary $(n=8)$ or secondary $(n=7)$ total repair. In 14 cases the VSD closure was successful and correlated with a favorable postoperative right ventricular/left ventricular pressure ratio $(\mathrm{pRV} / \mathrm{pLV})($ Table $\mathrm{V})$. The remaining patient, a 12.8-year-old girl with mediumsized pulmonary arteries and 4 stenotic MAPCAs, who underwent primary 1-stage unifocalization and repair, postoperatively had a hypersystemic right ventricle, despite a reassuring intraoperative pulmonary flow study (a mean pulmonary artery pressure of 29 $\mathrm{mm} \mathrm{Hg}$ with a cardiac index of $2.5 \mathrm{~L} / \mathrm{min}$ per square meter). The VSD was reopened and the child could be weaned from cardiopulmonary bypass, but she died in the early postoperative period. Postmortem lung microscopy revealed diffuse pulmonary vascular obstructive disease. This was the only failure of the intraoperative flow study to ascertain the suitability for ventricular septation. In the remaining 8 patients, mean pulmonary artery pressures detected at the steady state (48 hours after the operation) closely approximated the values measured during the flow study (difference of means $=-4 \%$ [95\% CI: $-20 \%$ to $11 \%$ ]; $P=.2$ ), with a $\mathrm{pRV} / \mathrm{pLV}$ ranging from 0.35 to 0.65 (Table VI). Therefore accuracy of this test in predicting 
Table VI. Hemodynamic data of patients evaluated with the flow study

\begin{tabular}{|c|c|c|c|c|c|c|c|c|c|c|c|c|}
\hline \multirow[b]{2}{*}{ Pt. No. } & \multirow[b]{2}{*}{$\begin{array}{l}\text { Age } \\
(\mathrm{mo})\end{array}$} & \multirow[b]{2}{*}{$\begin{array}{c}\text { Previous } \\
\text { RVOTR }\end{array}$} & \multirow[b]{2}{*}{$\begin{array}{c}\text { TNPAI } \\
\left(\mathrm{mm}^{2} / \mathrm{m}^{2}\right)\end{array}$} & \multicolumn{2}{|c|}{ During flow study } & \multirow[b]{2}{*}{$\begin{array}{c}\text { VSD } \\
\text { status }\end{array}$} & \multicolumn{2}{|c|}{ After 48 h postop } & \multicolumn{4}{|c|}{ Postop cardiac catheterization } \\
\hline & & & & $\begin{array}{c}\text { Indexed } \\
\text { peak flow } \\
(\mathrm{L} / \mathrm{min})\end{array}$ & $\begin{array}{c}\text { Mean } \\
\text { PAP } \\
(m m \mathrm{Hg})\end{array}$ & & $\begin{array}{c}\text { Mean } \\
\text { PAP } \\
(m m \mathrm{Hg})\end{array}$ & $\begin{array}{c}p R V / \\
p L V\end{array}$ & $\begin{array}{c}\text { Interval } \\
\text { (mo) }\end{array}$ & $\begin{array}{c}\text { Mean } \\
\text { PAP } \\
(m m \mathrm{Hg})\end{array}$ & $\begin{array}{c}p R V / \\
p L V\end{array}$ & $\begin{array}{l}Q p / \\
Q s\end{array}$ \\
\hline 1 & 154 & No & 184 & 2.5 & 29 & Reopened & - & - & - & - & - & - \\
\hline 2 & 14 & Yes & 214 & 2.86 & 20 & Closed & 22 & 0.65 & 13 & 24 & 0.44 & $1: 1$ \\
\hline 3 & 84 & No & 151 & 2.5 & 24 & Closed & 25 & 0.6 & 13 & 17 & 0.35 & $1: 1$ \\
\hline 4 & 118 & No & 355 & 2.65 & 18 & Closed & 18 & 0.5 & 12 & 14 & 0.25 & $1: 1$ \\
\hline 5 & 71 & No & 236 & 2.68 & 22 & Closed & 21 & 0.5 & 11 & 20 & 0.33 & $1: 1$ \\
\hline 6 & 21 & No & 365 & 2.6 & 30 & Closed & 26 & 0.41 & 10 & 22 & 0.62 & $1: 1$ \\
\hline 7 & 84 & No & 234 & 2.5 & 25 & Closed & 25 & 0.5 & 6 & 24 & 0.5 & $1: 1$ \\
\hline 8 & 58 & No & 319 & 2.5 & 27 & Closed & 23 & 0.35 & 8 & 19 & 0.42 & $1: 1$ \\
\hline 9 & 38 & Yes & 152 & 2.85 & 27 & Closed & 25 & 0.45 & & Not pe & ormed & \\
\hline
\end{tabular}

RVOTR, Right ventricular outflow tract reconstruction; TNPAI, total neopulmonary arterial index; PAP, pulmonary artery pressure; VSD, ventricular septal defect; $p R V / p L V$, right ventricular/left ventricular pressure ratio; $Q p / Q s$, pulmonary/systemic flow ratio.

the postrepair mean pulmonary artery pressure was $89 \%$ (95\% CI: $51 \%-99 \%)$.

All survivors had a smooth postoperative course. There were a few minor complications, including transient dysfunction of the left hemidiaphragm $(n=1)$, left upper lobe bronchopneumonia $(\mathrm{n}=1)$, and prolonged episodes of bronchospasm $(n=4)$. Mean and median hospital stays were $11 \pm 5$ days and 10 days, respectively (range 6-22 days). At discharge, all patients were in stable sinus rhythm $(\mathrm{n}=13)$ or had DDD mode pacing $(n=1)$. Echocardiography revealed absence of residual intracardiac defects and good right ventricular function in all. Bronchospasm persisted in 3.

Chromosome 22q11 microdeletion. Chromosome 22q11 microdeletion did not influence the surgical treatment of the disease, the genotype and the anatomic phenotype being completely unrelated in the reported series. ${ }^{18}$

Follow-up. Follow-up ranged from 6 to 36 months with mean and median intervals of $18 \pm 12$ and 13.5 months, respectively. One patient underwent successful reoperation 2 months after the initial operation for acute endocarditis of the right ventricle-pulmonary artery homograft (postoperative $\mathrm{pRV} / \mathrm{pLV}=0.3$ ). The patient with congenital heart block required endocardial pacemaker implantation 6 months after the operation for dysfunction of old epicardial leads.

Eleven patients underwent routine follow-up cardiac catheterization 6 to 23 months after the repair (mean 14 \pm 6 , median 13 months) (Fig 4). One patient with a peak right ventricular pressure of $53 \mathrm{~mm} \mathrm{Hg}(\mathrm{pRV} / \mathrm{pLV}=$ 0.53) underwent successful stent placement into the right pulmonary artery distal to a right upper lobe MAPCA unifocalization 20 months after the operation. Eleven months later, a right ventricular pressure of $35 \mathrm{~mm} \mathrm{Hg}$ was found by 2-dimensional Doppler echocardiography. Another patient underwent successful bilateral balloon dilatation of pulmonary arteries 11 months after the operation, with a subsequent fall of $\mathrm{pRV} / \mathrm{pLV}$ from 0.5 to 0.33 . A third patient had a discrete stenosis at the anastomotic site of a unifocalized right inferior lobe MAPCA, a discrete stenosis of the origin of the left pulmonary artery, and residual patency of a small anastomotic collateral. Thirteen months after the operation, this patient underwent both successful balloon dilatation of the stenoses and coil occlusion of the collateral, with a reduction of $\mathrm{pRV} / \mathrm{pLV}$ from 0.62 to 0.44 . Seven of 8 survivors after intraoperative flow study, $11 \pm 3$ months postoperatively (median 11.5, range 6-13 months), underwent cardiac catheterization, which showed stable or decreasing mean pulmonary artery pressures compared with those recorded during flow study (difference of means: $-20 \%$ [95\% CI: $-43 \%$ to $4 \%$ ]; $P=.07$ ) and $\mathrm{pRV} / \mathrm{pLV}$ values comparable with those measured 48 hours after the operation (difference of means: $-16 \%$ [95\% CI: $40 \%$ to $8 \%$ ]; $P=.3$ ) (Table VI). Four patients also underwent nuclear perfusion scans 1 to 7 days after follow-up cardiac catheterization. They all showed symmetrical distribution of pulmonary blood supply.

In March 1998, all survivors were in New York Heart Association class I, without medications. Their mean peak right ventricular pressures assessed by either cardiac catheterization $(n=11)$ or 2-dimensional Doppler echocardiography $(n=14)$ were $43 \pm 11 \mathrm{~mm} \mathrm{Hg}$ (median 45, range 23-63) and $40 \pm 7 \mathrm{~mm} \mathrm{Hg}$ (median 40 , range 30-60), respectively. On the whole, the most persistent late symptoms were related to bronchospasm (up to 1 year after the operation in 2 cases).

\section{Discussion}

Since unifocalization was introduced, ${ }^{19}$ several staged procedures have been advocated in preparation for complete repair. However, no consensus has been 

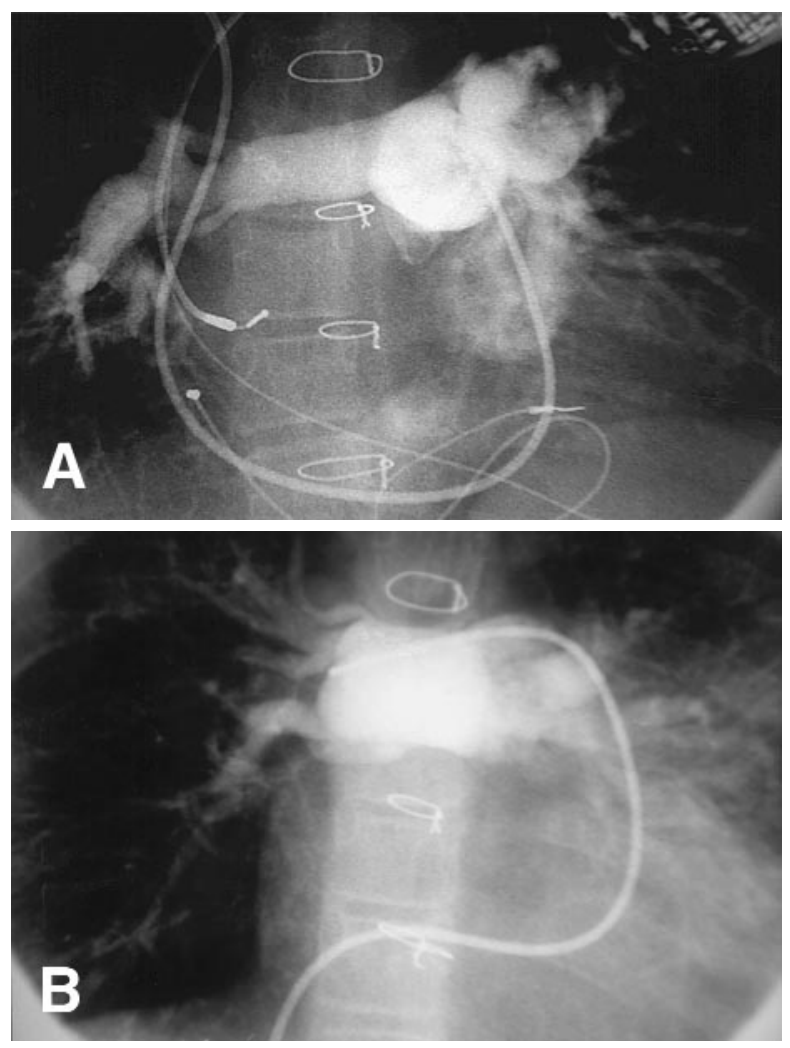

Fig 4. Angiographic evidence of totally unifocalized pulmonary arterial tree. A, Postoperative angiogram of case depicted in Fig 1. B, Postoperative angiography of case depicted in Fig 2.

reached for crucial issues, for example, treatment of hypoplastic pulmonary arteries ${ }^{3,6,9}$ strategy of unifocalization, ${ }^{5,9,20,21}$ source of blood supply to the unifocalized pulmonary circulation, ${ }^{4-7,9}$ and criteria for repair. ${ }^{5,7,10}$ Unfortunately, most of these multistage approaches have been inadequate in terms of cumulative morbidity and mortality, real potential for repair, and functional results of the repair itself. ${ }^{4-7}$

One-stage total unifocalization, recently introduced by Reddy, Liddicoat, and Hanley, ${ }^{11}$ has been accomplished with any kind of true pulmonary arterial anatomy using either a midline ${ }^{11,13}$ or a clamshell ${ }^{12}$ approach. Combined cardiac repair has been possible in $80 \%$ to $100 \%$ of cases. ${ }^{11-13}$ It is suggested that, the earlier in infancy the unifocalization is performed, the better the long-term results are, owing to prevention of both shear stress lesions of MAPCAs and pulmonary vascular obstructive disease in distinct lung segments. ${ }^{11,13,14}$

Our policy differed slightly from that of primary 1stage unifocalization in all cases. In fact, we considered primary unifocalization unfeasible in the not so rare cases (up to $73 \%$ ) of severely hypoplastic pulmonary
Table VII. Surgical management of MAPCAs

\begin{tabular}{lll}
\hline & $\begin{array}{c}\text { Primary repair } \\
(n=8)\end{array}$ & $\begin{array}{c}\text { Secondary repair } \\
(n=7)\end{array}$ \\
\hline $\begin{array}{l}\text { No. of MAPCAs per patient } \\
\text { Mean } \pm \text { SD }\end{array}$ & $3.6 \pm 1.6$ & $2.3 \pm 0.9$ \\
$\quad \begin{array}{l}\text { Median } \\
\text { Range }\end{array}$ & 4 & 2 \\
No. of anastomoses per patient & $1-6$ & $1-4$ \\
$\quad$ Mean \pm SD & $3 \pm 1.6$ & $1.1 \pm 0.4$ \\
Median & 3 & 1 \\
Range & $1-5$ & $1-2$ \\
No. of ligations per patient & & \\
$\quad$ Mean \pm SD & $0.6 \pm 0.7$ & $1.1 \pm 1$ \\
Median & 0.5 & 1 \\
Range & $0-2$ & $0-3$ \\
\hline
\end{tabular}

MAPCAs, Major aortopulmonary collateral arteries.

arteries combined with MAPCAs perfusing only a minor proportion of lung segments. ${ }^{22}$ This reflected 2 main concerns. First, hypoplasia of central pulmonary arteries would not provide adequate support for anastomosing transected isolated collaterals. Second, underdeveloped peripheral arborization of lung segments served by hypoplastic true pulmonary arteries would lead to preferential flow into the unifocalized collaterals, resulting in uneven pulmonary blood flow distribution. We preferred to treat such an anatomic arrangement by first allowing forward flow into true pulmonary arteries to promote both their central and peripheral growth ${ }^{15,23}$ and subsequently undertaking midline 1-stage unifocalization and cardiac repair. ${ }^{11,13}$

To sort patients for either preliminary RVOT reconstruction or primary 1-stage unifocalization and repair, based on our previous experience with PAI for repair of complex PA and VSD, ${ }^{17}$ we arbitrarily referred to a TNPAI cutoff value of less than 150 or more than 150 $\mathrm{mm}^{2} / \mathrm{m}^{2}$, respectively. In this series, a TNPAI less than $150 \mathrm{~mm}^{2} / \mathrm{m}^{2}$ always correlated with a preoperative PAI less than $100 \mathrm{~mm}^{2} / \mathrm{m}^{2}$ (very small to small pulmonary arteries) and with dominance of pulmonary arteries versus MAPCAs with respect to number of lung segments supplied $(13.9 \pm 1.1$ vs $8.6 \pm 5.8)$.

All 7 patients undergoing RVOT reconstruction had a significant development of true pulmonary arteries (Fig 3 ) and successfully underwent secondary 1-stage unifocalization and cardiac repair. The growth of native pulmonary arteries facilitated the recognition of lung segments with dual blood supply. ${ }^{4,15}$ Collaterals involved in dual lung supply were usually ligated at unifocalization. Because of the lesser occurrence of MAPCAs in this subgroup of patients and the routine ligation of those responsible for dual supply, unifocalization during secondary procedures involved a lesser 
number of anastomoses than did primary procedures (Table VII).

In our experience, the best indicator of suitability for VSD closure at the time of 1-stage unifocalization and repair was the intraoperative pulmonary flow study. ${ }^{14}$ Used in the more recent part of the series $(n=9)$, the flow study proved reliable in all but the first case. Postmortem revision of this case showed the presence of variable degrees of diffuse pulmonary vascular disease. The ensuing pulmonary vasoreactivity was probably further compounded by recurrent postoperative metabolic acidosis associated with hypoxemia (rightto-left atrial shunting through an artificial 1-way atrial septal defect) and postoperative bleeding.

Our early results with both primary and secondary 1stage complete unifocalization and repair of PA, VSD, and MAPCAs are sound, with a $93 \%$ rate of both early survival and successful complete repair (95\% CI: 66\%$100 \%)$. RVOT reconstruction was needed by patients with limited collateral-dependent pulmonary blood flow, who thus had early cyanosis. On the other hand, patients with predominant collateral-dependent pulmonary blood flow were referred to us only later in life. Eventually, patients with RVOT reconstruction underwent repair earlier than those having primary repair (Table II). On the whole, 1-stage unifocalization and repair were done later in life in a greater proportion of our patients than would be expected from current trends toward early correction. ${ }^{11,13,14}$ The greatest risk of a delayed approach is the occurrence of pulmonary vascular obstructive disease, which is difficult to predict and quantify in PA, VSD, and MAPCAs owing to multifocal pulmonary blood supply and progressive development of collateral stenoses. ${ }^{19,24-26}$ On a speculative ground, the finding of stenotic collaterals in older patients does not necessarily mean that the distal pulmonary vascular bed is "protected." In fact, such stenoses might occur even after the development of pulmonary vascular obstructive disease, as suggested by the only death that occurred in this series.

Despite such a relatively late age at repair, at intermediate follow-up all survivors have low right ventricular pressure, generally balanced distribution of blood flow, and low need for major interventional procedures on the reconstructed pulmonary arteries. Interestingly, the mean pulmonary artery pressure and/or the pRV/ pLV at follow-up cardiac catheterization compared favorably with those recorded both during flow study and 48 hours after the operation. Such data further corroborate the adequacy of the flow study in discriminating suitability for repair and possibly support the thesis of an improved lung condition once normal hemodynamics is restored.
Finally, the occurrence of chromosome 22q11 microdeletion in cases of PA, VSD, and MAPCAs has recently been reported in association with a peculiar anatomic phenotype ${ }^{27}$ with an implicit need for more complex surgical procedures. ${ }^{28}$ Our analysis failed to demonstrate a similar correlation, probably because of the very limited number of patients.

Limitations of the study. First, the small number of patients of this series does not allow meaningful statistical analysis. Second, in consideration of the somewhat old average age of the patients at the time of unifocalization (with the related risk of fully developed pulmonary vascular obstructive disease), the good results achieved in this series might express a spontaneous selection of patients with "protected" pulmonary circulation. Finally, the shortness of the follow-up interval does not allow definitive conclusions on the fate of pulmonary circulation of unifocalized patients.

\section{Conclusion}

In conclusion, preoperative morphologic criteria allow the identification of a subgroup of patients with PA, VSD, and MAPCAs who are likely to benefit from an intermediate palliative stage (RVOT reconstruction). Both primary and secondary 1-stage complete unifocalization are easily accomplished in most cases. Intraoperative assessment of the compliance of the unifocalized pulmonary vascular bed may lead to safe evaluation of suitability for ventricular septation. All the aforementioned steps, within the framework of an "integrated approach," may lead to optimal intermediate results of complete repair of PA, VSD, and MAPCAs with low $\mathrm{pRV} / \mathrm{pLV}$.

We gratefully acknowledge the technical assistance of Giuseppe Bolla and the skillful artwork of Emilio Ferretti, MD.

\section{REFERENCES}

1. Millikan JS, Puga FJ, Danielson GK, Schaff HV, Julsrud PR, Mair DD. Staged surgical repair of pulmonary atresia, ventricular septal defect, and hypoplastic, confluent pulmonary arteries. J Thorac Cardiovasc Surg 1986;91:818-25.

2. Freedom RM, Pongiglione G, Williams WG, Trusler GA, Rowe RD. Palliative right ventricular outflow tract construction for patients with pulmonary atresia, ventricular septal defect, and hypoplastic pulmonary arteries. J Thorac Cardiovasc Surg 1983; 86:24-36.

3. Watterson KG, Wilkinson JL, Karl TR, Mee RBB. Very small pulmonary arteries: central end-to-side shunt. Ann Thorac Surg 1991;52:1132-7

4. Sullivan ID, Wren C, Stark J, de Leval MR, Macartney FJ, Deanfield JE. Surgical unifocalization in pulmonary atresia and ventricular septal defect. A realistic goal? Circulation 1988;78 (Suppl):III5-13.

5. Puga FJ, Leoni FE, Julsrud PR, Mair DD. Complete repair of pul- 
monary atresia, ventricular septal defect, and severe peripheral arborization abnormalities of central pulmonary arteries. J Thorac Cardiovasc Surg 1989;98:1018-29.

6. Sawatari K, Imai Y, Kurosawa H, Isomatsu Y, Momma K. Staged operation for pulmonary atresia and ventricular septal defect with major aortopulmonary collateral arteries. J Thorac Cardiovasc Surg 1989;98:738-50.

7. Iyer KS, Mee RBB. Staged repair of pulmonary atresia with ventricular septal defect and major systemic to pulmonary artery collaterals. Ann Thorac Surg 1991;51:65-72.

8. Marelli AJ, Perloff JK, Child JS, Laks H. Pulmonary atresia with ventricular septal defect in adults. Circulation 1994;89:243-51.

9. Yagihara T, Yamamoto F, Nishigaki K, Matsuki O, Uemura H, Isizaka $\mathrm{T}$, et al. Unifocalization for pulmonary atresia with ventricular septal defect and major aortopulmonary collateral arteries. J Thorac Cardiovasc Surg 1996;112:392-402.

10. Shimazaki Y, Tokuan Y, Lio M, Nakano S, Matsuda H, Blackstone EH, et al. Pulmonary artery pressure and resistance late after repair of tetralogy of Fallot with pulmonary atresia. J Thorac Cardiovasc Surg 1990;100:425-40.

11. Reddy VM, Liddicoat JR, Hanley FL. Midline one-stage complete unifocalization and repair of pulmonary atresia with ventricular septal defect and major aortopulmonary collaterals. J Thorac Cardiovasc Surg 1995;109:832-45.

12. Luciani GB, Wells WJ, Khong A, Starnes VA. The clamshell incision for bilateral pulmonary artery reconstruction in tetralogy of Fallot with pulmonary atresia. J Thorac Cardiovasc Surg 1997; 113:443-52.

13. Tchervenkov CI, Salasidis G, Cecere R, Béland MJ, Jutras L, Paquet M, et al. One-stage midline unifocalization and complete repair in infancy versus multiple-stage unifocalization followed by repair for complex heart disease with major aortopulmonary collaterals. J Thorac Cardiovasc Surg 1997;114:727-37.

14. Reddy MV, Petrossian E, McElhinney DB, Moore P, Teitel DF, Hanley FL. One-stage complete unifocalization in infants: when should the ventricular septal defect be closed? J Thorac Cardiovasc Surg 1997;113:858-68.

15. Pagani FD, Cheatham JP, Beekman RH III, Lloyd TR, Mosca RS, Bove EL. The management of tetralogy of Fallot with pulmonary atresia and diminutive pulmonary arteries. J Thorac Cardiovasc Surg 1995;110:1521-33.

16. Nakata S, Imai Y, Takanashi Y, Kurosawa H, Tezuka K, Nakazawa $\mathrm{M}$, et al. A new method for quantitative standardization of cross-sectional areas of the pulmonary arteries in congenital heart diseases with decreased pulmonary blood flow. J Thorac Cardiovasc Surg 1984;88:610-9.

17. Carotti A, Seddio F, Guccione P, Bolla G, Squitieri C, Marianeschi $\mathrm{SM}$, et al. Efficacia della ricostruzione palliativa dell'efflusso ventricolare destro nel trattamento stadiato dell'atresia polmonare con difetto interventricolare. G Ital Cardiol 1995;25 (Suppl):II9.

18. Digilio MC, Marino B, Grazioli S, Agostino D, Giannotti A, Dallapiccola B. Comparison of occurrence of genetic syndromes in ventricular septal defect with pulmonary stenosis (classic tetralogy of Fallot) versus ventricular septal defect with pulmonic atresia. Am J Cardiol 1996;77:1375-6.

19. Haworth SG, Macartney FJ. Growth and development of pulmonary circulation in pulmonary atresia with ventricular septal defect and major aortopulmonary collateral arteries. Br Heart J 1980;44:14-24.

20. Pacifico AD, Allen RH, Colvin EV. Direct reconstruction of pulmonary artery and intracardiac repair of pulmonary atresia with ventricular septal defect. Am J Cardiol 1985;55:1647-9.

21. Barbero-Marcial M, Rizzo A, Lopes AA, Bittencourt D, Junior
JOA, Jatene AD. Correction of pulmonary atresia with ventricular septal defect in the absence of the pulmonary trunk and the central pulmonary arteries (so-called truncus type IV). J Thorac Cardiovasc Surg 1987;94:911-4.

22. Anderson RH, Devine WA, Del Nido P. The surgical anatomy of tetralogy of Fallot with pulmonary atresia rather than pulmonary stenosis. J Card Surg 1991;6:41-59.

23. Rome JJ, Mayer JE, Castañeda AR, Lock YE. Tetralogy of Fallot with pulmonary atresia: rehabilitation of diminutive pulmonary arteries. Circulation 1993;88:1691-8.

24. Liao P, Edwards WD, Julsrud PR, Puga FJ, Danielson GK, Feldt RH. Pulmonary blood supply in patients with pulmonary atresia and ventricular septal defect. J Am Coll Cardiol 1985;6:1343-50.

25. Jefferson K, Rees S, Somerville J. Systemic arterial supply to the lungs in pulmonary atresia and its relation to pulmonary artery development. Br Heart J 1972;34:418-27.

26. Rabinovich M, Herrera-DeLeon V, Castañeda AR, Reid L. Growth and development of pulmonary vascular bed in patients with tetralogy of Fallot with or without pulmonary atresia. Circulation 1981;64:1234-49.

27. Chessa M, Butera G, Bonhoeffer P, Iserin L, Kachaner J, Lyonnet $\mathrm{S}$, et al. Relation of genotype 22q11 deletion to phenotype of pulmonary vessels in tetralogy of Fallot and pulmonary atresiaventricular septal defect. Heart 1998;79:186-90.

28. Hofbech M, Rauch A, Buheitel G, Leipold G, von der Emde J, Pfeiffer R, et al. Monosomy 22q11 in patients with pulmonary atresia, ventricular septal defect, and major aortopulmonary collateral arteries. Heart 1998;79:180-5.

\section{Discussion}

Dr Mohan Reddy (San Francisco, Calif). At the University of California at San Francisco, since starting 1stage unifocalization in 1992, we now have nearly 100 patients. As our approach has evolved, our strategy has changed a bit. PA with VSD and MAPCAs is a complex and heterogenous lesion with regard to pulmonary vasculature, and this necessitates a neutralization of surgical strategy.

Currently we perform complete unifocalization and repair in over two thirds of our patients; that includes closure of the VSD. In the remaining third, about three quarters of these patients have undergone complete unifocalization in 1 stage and the VSD was left open, and in the last 50 or so patients we have used exclusively the intraoperative flow study to determine the feasibility of VSD closure. In the remaining few patients, about $5 \%$ to $8 \%$ of the total population, we have used staged unifocalization via thoracotomies.

I have 3 relatively simple questions: In patients in whom you created a right ventricle-pulmonary artery conduit, you did not control the collaterals during the bypass. What $\mathrm{pH}$ strategy have you used and did you encounter any neurologic problems with this approach?

Second, what is your approach currently to a neonate or a young infant who is symptomatic or asymptomatic and when would you like to operate on this patient?

Finally, have you seen any transient liver dysfunction in the postoperative period, which needs to be managed very aggressively in terms of the glucose and potassium?

Dr Carotti. Thank you, Dr. Reddy, for your comments. Our approach differs slightly from your policy in San Francisco. 
We know that in most cases you proceed with 1-stage unifocalization. We elect, instead, to stage the repair in patients with severely hypoplastic pulmonary arteries and few collaterals supplying a minor proportion of lung segments rather than doing the 1-stage operation. In fact, we suspect that in patients with "dominant" hypoplastic pulmonary arteries undergoing a primary complete unifocalization there is a reasonable risk of unsuitability for primary VSD closure. Furthermore, we believe that, after palliative RVOT reconstruction, there is also a reasonable chance of insufficient growth of the true pulmonary arteries owing to preferential runoff into unifocalized collaterals. Conversely, by staging the repair, by first performing a palliative RVOT reconstruction, we believe that the true pulmonary arteries can develop more consistently in size and that, therefore, the overall probability of total repair at the time of unifocalization is increased.

With respect to your first question concerning $\mathrm{pH}$ strategy, we always used the $\alpha$-stat strategy and never encountered any neurologic problem. As a matter of fact, we always tried to run very short periods of cardiopulmonary bypass, keeping the temperature at about $22^{\circ} \mathrm{C}$, and to perfuse the patient with high flows, such as 150 up to $200 \mathrm{~mL} / \mathrm{kg}$ per minute.

With respect to the approach to a symptomatic infant, since we started this protocol we have never had the opportunity to operate on a neonate or young infant. However, we did operate on our patients as soon as the cardiologist referred them to us. We would like very much to start doing the single-stage operation in young infants. We know that you do so and Dr Tchervenkov does so. We plan to operate on those patients within the ages of 6 months to 1 year.

We never observed any problems with liver dysfunction or, more in general, multiorgan dysfunction. Actually, we had only transient hemoglobinuria in the early postoperative course in patients who underwent a very long run of cardiopulmonary bypass during 1-stage approaches. On the other hand, we did not have any other problem, as demonstrated by the very short mean hospital stay.

Dr Christo I. Tchervenkov (Montreal, Quebec, Canada). I would like to congratulate you on excellent results. You have achieved repairability in over $90 \%$ of the patients, which is significantly higher than the previously published large studies with a multistage approach. We have also evolved at the Montreal Children's Hospital from a multistage approach to currently the single-stage approach, and we presented our results last year at the Association meeting in Washington. My questions will focus on the PAI, and I applaud your efforts to try to develop predictive criteria for the feasibility of single-stage repair versus staged repair in these patients.

Our observation has been that the PAI in the patient with tetralogy of Fallot as determined by preoperative angiogram or echocardiography frequently underestimates the true size of the pulmonary arteries because they are simply underfilled. We have consistently found in the small patients that in diminutive arteries, both in regular tetralogy and tetralogy with PA of MAPCAs, that the diminutive arteries are fre- quently 1 or 2 or perhaps $3 \mathrm{~mm}$ larger in diameter than the preoperative prediction.

Have you tried to correlate your preoperative assessment of size and index to the intraoperative findings? Is it possible that some patients who are over that cutoff point of 150 $\mathrm{mm} / \mathrm{m}^{2}$ are subjected to the multistage approach and yet could actually undergo the definitive operation?

Second, what would you do with a patient who has no true pulmonary arteries and yet has an index less than $150 \mathrm{~mm} / \mathrm{m}^{2}$ ? What would you do with a patient who has an index of perhaps 120 and has no true pulmonary arteries that can be developed?

Third, our technique in Montreal has differed slightly from Frank Hanley's technique in San Francisco. We perform central dissection to get at the MAPCAs instead of the peripheral approach by opening the pleura. We go straight down to the aorta, particularly if it is a right descending aorta. It is actually quite easy to get at the collaterals without having to open the pleura at all. The second difference is that we do not hesitate to ligate collaterals, small MAPCAs that supply 1 or 2 segments, providing that the rest of the unifocalized arterial bed is adequate, or MAPCAs that go to regions of dual blood supply.

Dr Carotti. Thank you, Dr. Tchervenkov, for your questions.

With regard to the first question, in this small series we did not find discrepancy between the measurements or the index and the real dimension of pulmonary arteries. I would remind you that the original paper by Dr Nakata and associates did estimate the measure of the pulmonary arteries in patients with cyanotic heart diseases with a low filling volume of the pulmonary arteries.

Actually, it is always difficult to give a cutoff value and to decide what to do on the basis of it. I think that, on the two opposite extremes of the spectrum of the disease, it is easier to decide what kind of procedure to perform. However, it becomes more difficult to do so as you approach the "cutoff value" from each side.

With respect to what to do with a patient with a TNPAI of 120 , absent pulmonary arteries, and exclusive collaterals, we have not faced this problem yet. I would go ahead with the single-stage unifocalization and rely only on the intraoperative flow study in order to decide whether to close the VSD or not.

With respect to your question about the surgical technique, we definitely liked your modifications of Dr Hanley's approach. Actually, we never open the pleural spaces, because we previously had trouble sometimes during the multiple-stage approach through thoracotomies, facing severe pulmonary hemorrhage after manipulation of the lung. At present, we dissect the collaterals only by the transverse sinus approach; furthermore, we retrieve the more distal ones by incising the posterior pericardium and extending the dissection behind the left atrium.

With respect to the issue of small or anastomotic collaterals, we try to use all collaterals we can in cases of primary 1stage approach to either retrieve pulmonary segments or perform a distal pulmonary artery reconstruction. In cases of secondary 1-stage repair we usually ligate the anastomotic collaterals. It depends on one's general policy. 